\title{
Soil Water dynamic and water balance in a coral island: Zhaoshu Island, Xisha archipelago
}

\author{
Shengsheng $\mathrm{Han}^{1}$, Suxia $\mathrm{Liu}^{2}$, Xingguo $\mathrm{Mo}^{2}$, Lihu Yang ${ }^{3}$, and XF Song ${ }^{2}$ \\ ${ }^{1}$ Institute of Geographic Sciences and Natural Resources Research CAS \\ ${ }^{2}$ Institute of Geographic Sciences and Natural Resources Research Chinese Academy of \\ Sciences \\ ${ }^{3}$ Institute of Geographic Sciences and Natural Resources Research, Chinese Academy of \\ Sciences
}

July 27,2020

\begin{abstract}
Study of the soil water dynamic and water balance in coral islands is important to utilize and manage the limited freshwater resources of islands. In this study, we studied the soil water dynamic in Zhaoshu Island, Xisha archipelago using the observed data and the Richards equation, and analyzed the water balance of this island in the dry and wet seasons, respectively. The soil water movement showed that there was a dry soil layer at the depths between $40 \mathrm{~cm}$ and $160 \mathrm{~cm}$ of the soil profile in the dry season. The evaporation (Es) flux was low, but the transpiration (Er) could still absorb water from the capillary zone to maintain growth. In the wet season, the infiltration dominated the main process of soil water movement. The result of water balance showed the precipitation, the change values of water in the entire flow domain ( $V$ olume), bottomboundaryflux $(v$ Bot $)$, Er, Eswere $913 \mathrm{~mm}, 10 \mathrm{~mm}, 349 \mathrm{~mm}, 203 \mathrm{~mm}, 351 \mathrm{~mm}$, respectively fromOctober 2018 toSeptember 2019. Prect

\section{Soil Water dynamic and water balance in a coral island: Zhaoshu Island,Xishaarchipelago}

Running head: Soil Water dynamic and water balance in a coral island

Shengsheng. Han ${ }^{\text {ab }}$,Suxia. Liu ${ }^{a c^{*}}$, Xingguo. Mo ac, Lihu. Yang ${ }^{\mathrm{a}}$, and Xianfang. Song ac

${ }^{a}$ Key Laboratory of Water Cycle and Related Land Surface Processes, Institute of Geographic Sciences and Natural Resources Research, Chinese Academy of Sciences, Beijing 100101, PR China, ${ }^{b}$ University of Chinese Academy of Sciences, Beijing 100049, PR China, ${ }^{c}$ College of Resources and Environment, Sino-Danish Center, University of Chinese Academy of Sciences, Beijing 100049, PR China.

* Corresponding author at: 11A, Datun Road, Chaoyang District, Beijing 100101, China.

* Email address: liusx@igsnrr.ac.cn (Suxia. Liu )

Acknowledgements :

This project is supported by the Strategic Priority Research Program of the Chinese Academy of Sciences, Grant No.XDA13010303. We thank Prof. Changqi Zhu and his team members from the Institute of Rock and soil Mechanics, CAS and the fisherman in the island for the help in collecting data in the island. We thank all the team members in the project for pertinent comments at multiple Group Meetings. Thanks to Dr. Chaoyang Du in IGSNRR CAS for helping the first author in Hydrus-1D model simulation and the discussion in preliminary article writing.
\end{abstract}

\section{Availability of data:}


The data that support the findings of this study are available from the corresponding author upon reasonable request.

\section{Hosted file}

2Main text file.docx available at https://authorea.com/users/346360/articles/472434-soilwater-dynamic-and-water-balance-in-a-coral-island-zhaoshu-island-xisha-archipelago

\section{Hosted file}

3Tables.docx available at https://authorea.com/users/346360/articles/472434-soil-waterdynamic-and-water-balance-in-a-coral-island-zhaoshu-island-xisha-archipelago

\section{Hosted file}

Figure 1 Location of a) South China Sea, b) Xisha archipelago, c) Zhaoshu Island, and d) the soil water available at https://authorea.com/users/346360/articles/472434-soil-water-dynamic-and-waterbalance-in-a-coral-island-zhaoshu-island-xisha-archipelago

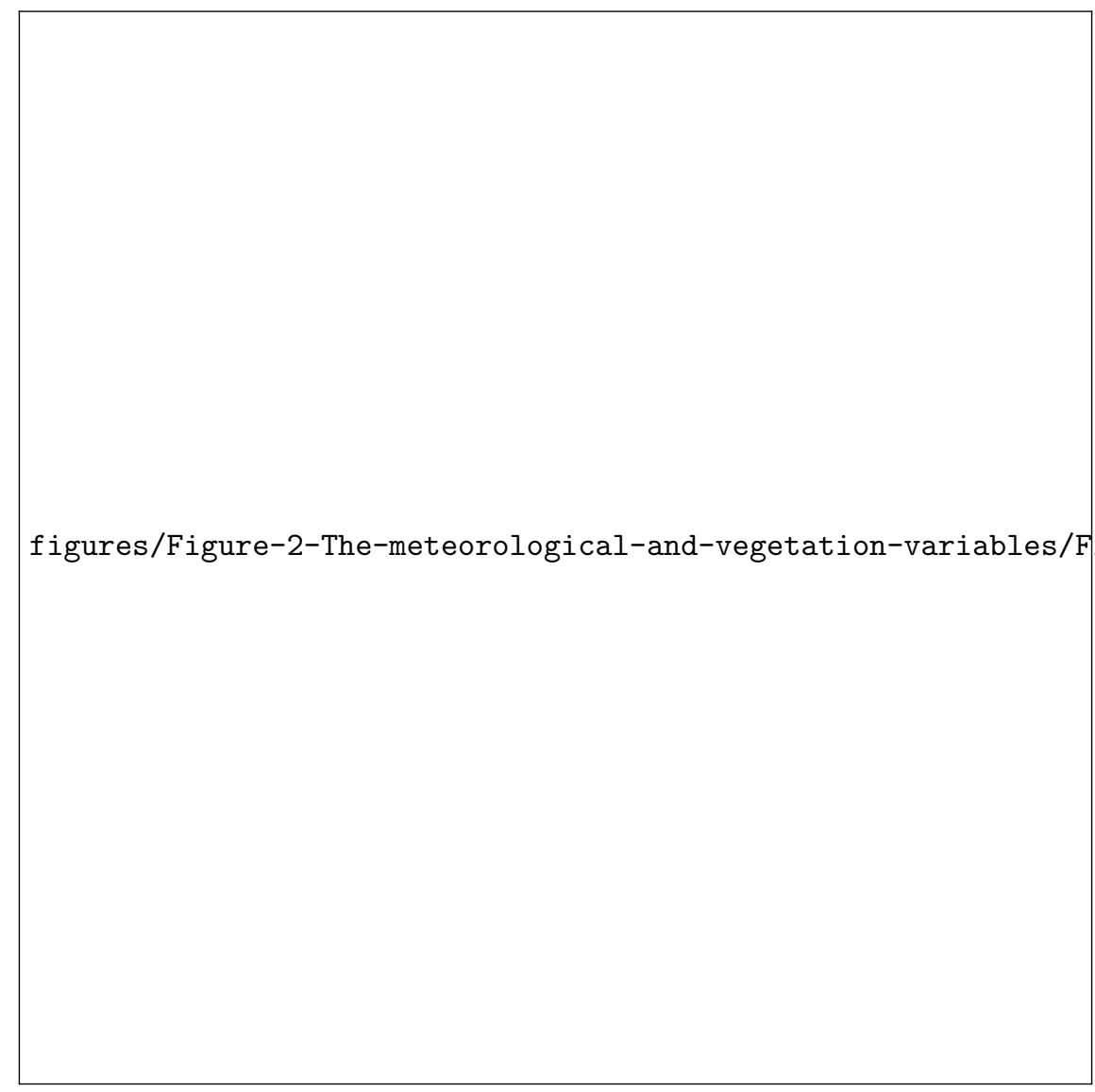




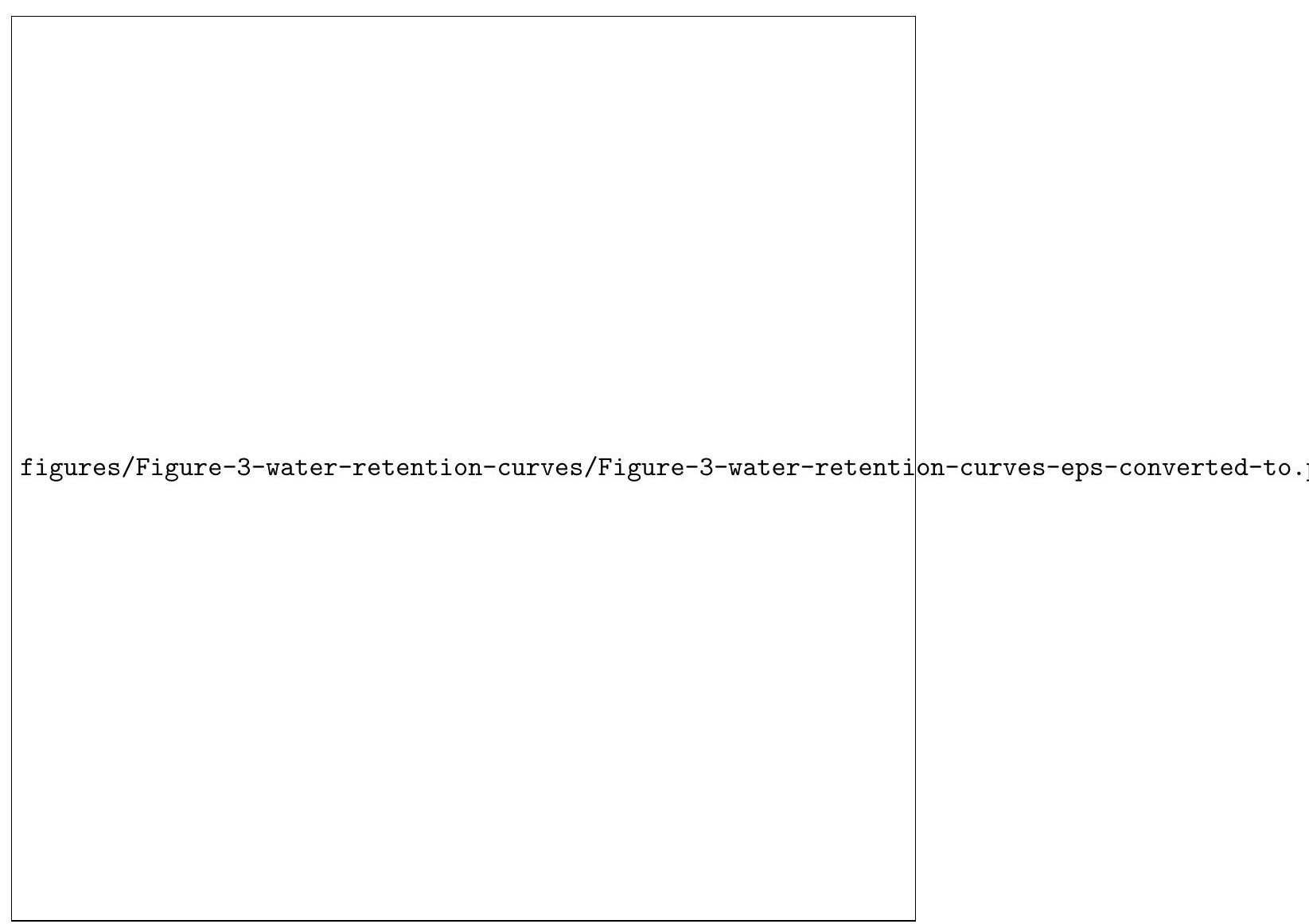




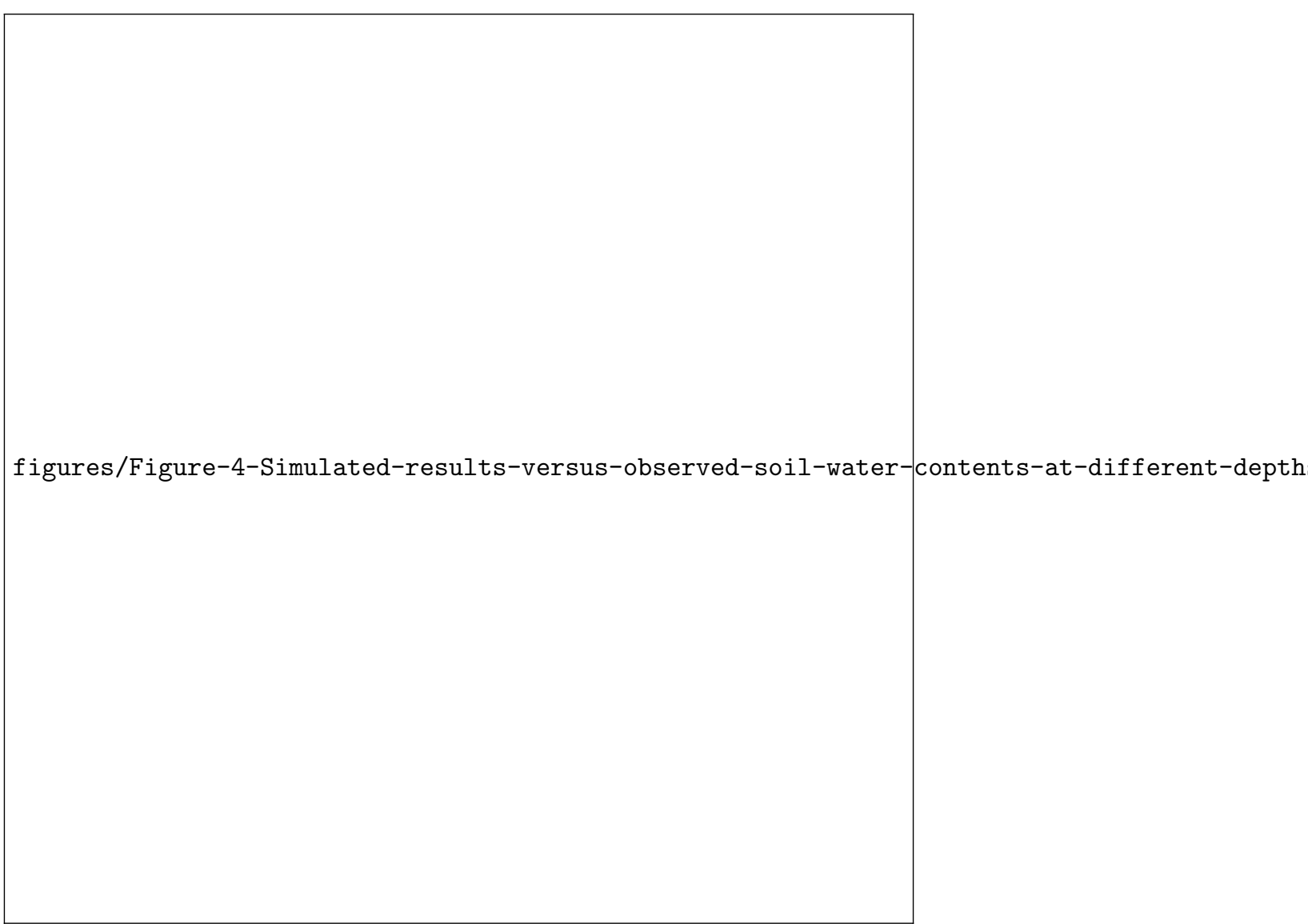




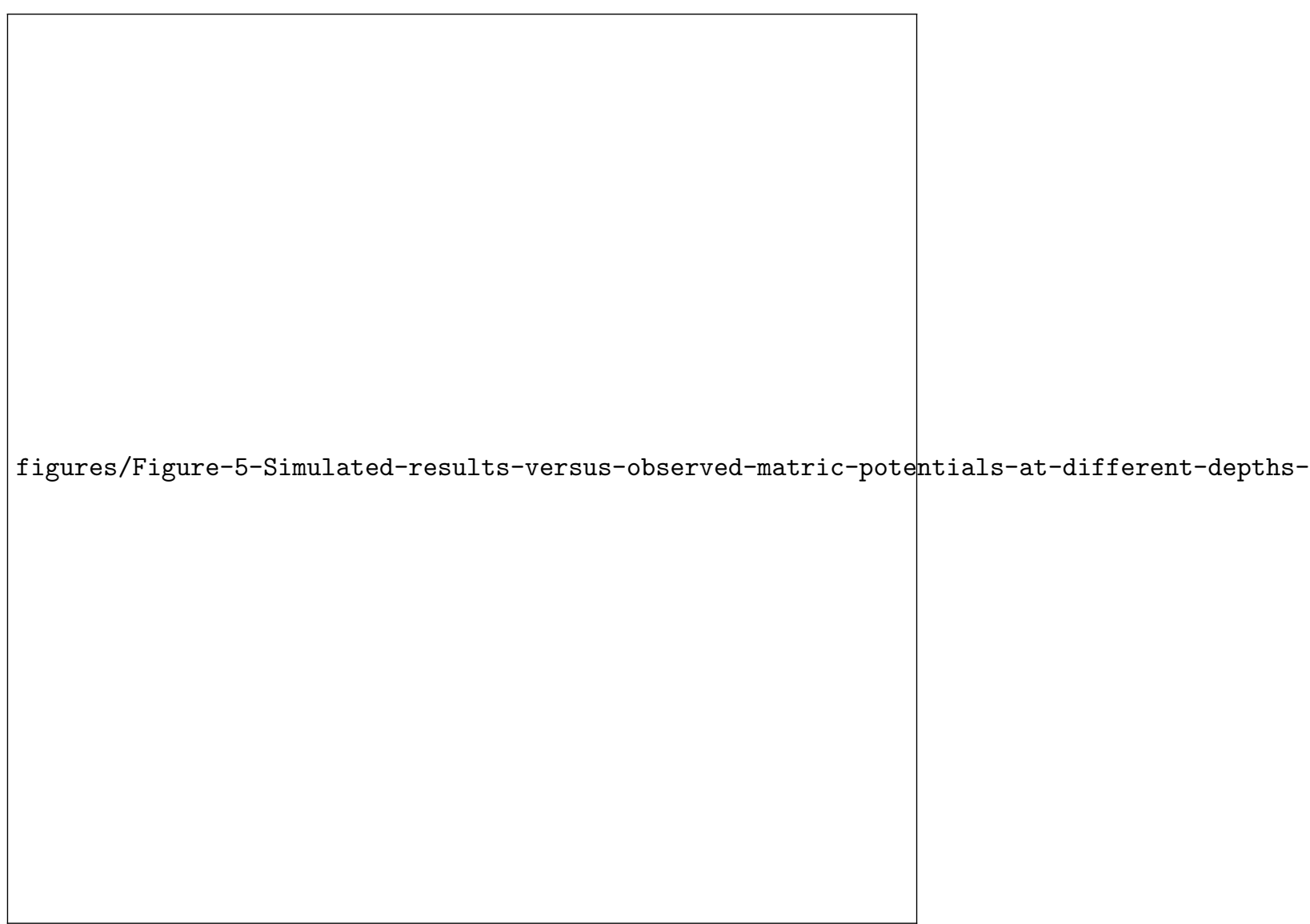



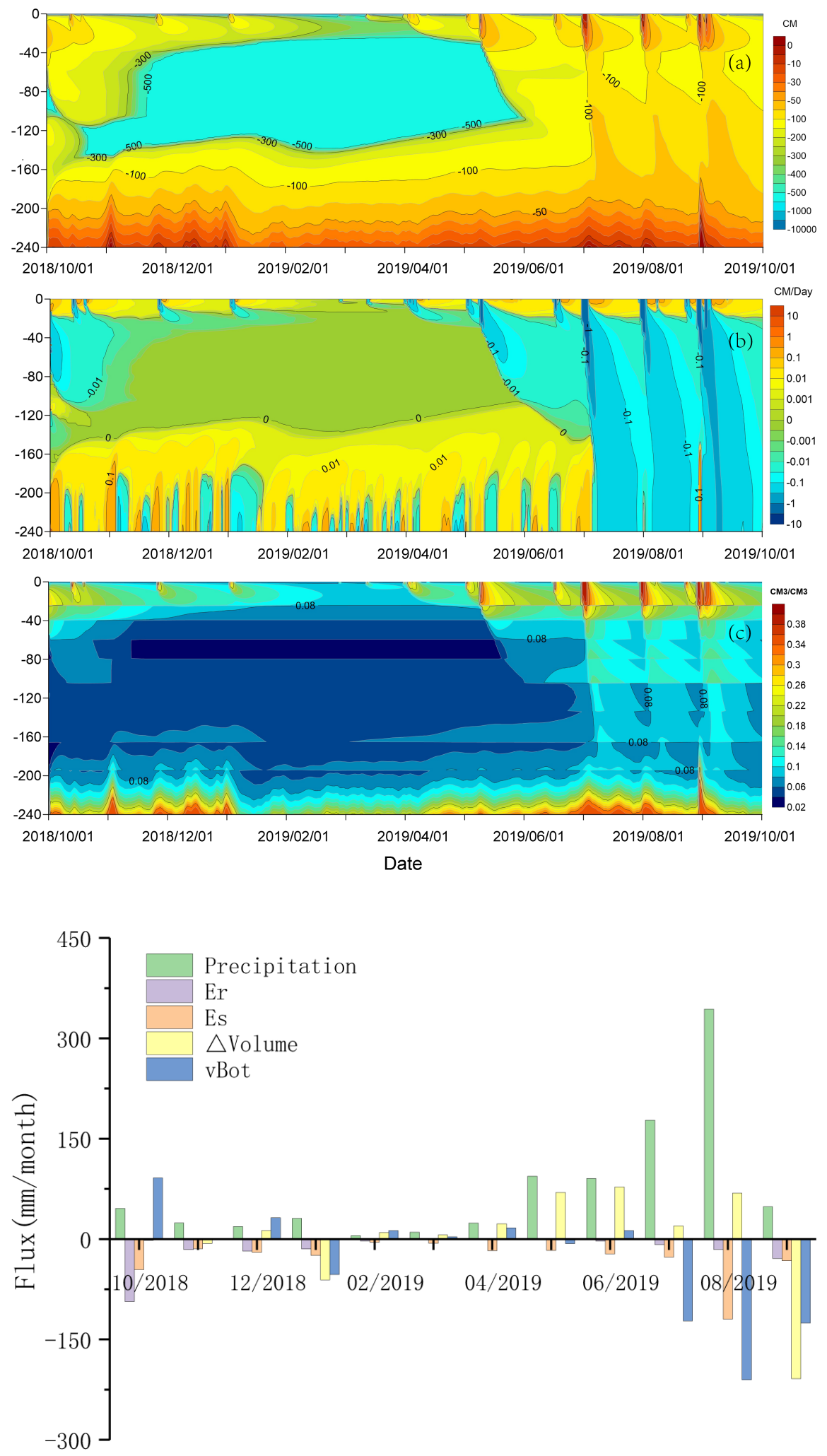


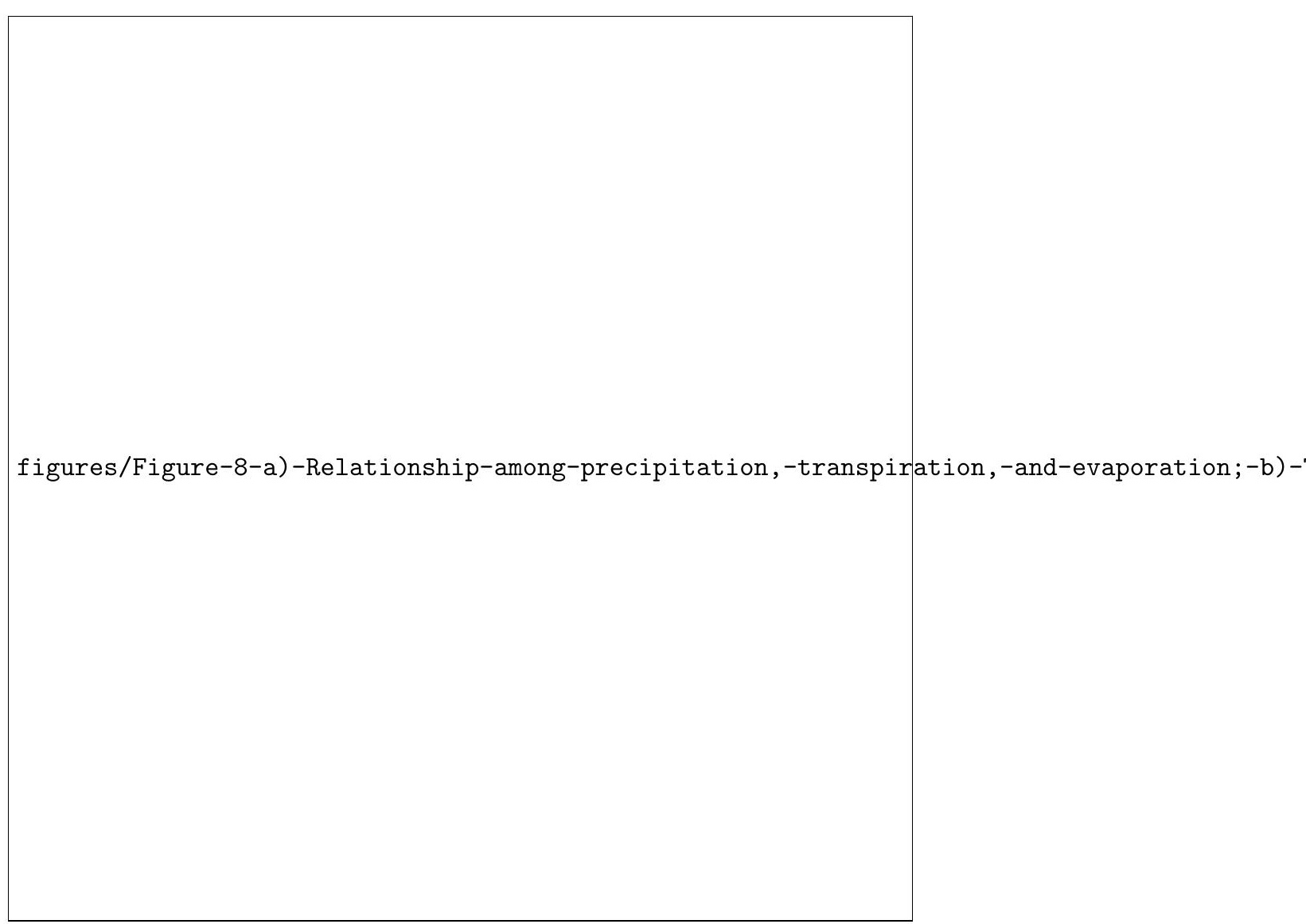

